\title{
ONE STEP BEFORE THE WORKBENCH: THE USE OF CHEMINFORMATICS TOOLS IN DRUG DISCOVERY
}

DOI: http://dx.doi.org/10.16891/2317-434X.v9.e2.a2021.pp995-996

\section{Vanderlan Nogueira Holanda}

Universidade Federal de Pernambucoa

E-mail: vanderlan.holanda@ufpe.br

The searching for new drugs has been the objective of several research groups around the world and involves a many area of research field such as biochemistry, chemistry, physics and biological sciences (Balasubramanian, 2021). Over past years, drugs that are used to treat diseases may have reduced effectiveness, such as the emergence of resistance to pharmacological treatment (Niu and $\mathrm{Li}, 2019$ ), showed a high toxicity index (Darwish et al., 2019) or being designated for other pathologies (Pillaiyar et al., 2020), as a result, the needing to produce new drugs increases. Additionally, since the end of 2019, it can be seen new diseases such as COVID19 may arise and require the scientific community to create drugs useful for treatment in a relatively shorter time than usual required (Mahdian et al., 2021).

The main limitation has been observed in the drug development process is the higher consumption of time and cost of the processes involved (Yasuo et al., 2021). Since the advent of genomics, proteomics and metabolomics, the search for targeted-specific drugs and less chance of causing adverse effects is considered a determining factor in the planning of bioactive compounds (Bril and Nosjean, 2018). In the course of time, the bioinformatics and theoretical medicinal chemistry tools have enabled different in silico approaches, such as pharmacokinetic and toxicological profile (ADMET), computer aided drug design (CADD), structure-activity structure-activity relationship (SAR), docking molecular and molecular dynamics were introduced in the field of drug research (Temml and Kutil, 2021).

The use of the in silico approach for the research of new drugs has grown in the international scientific scope in recent years. Take into consideration the number of publications per year containing the terms "in silico Drug Discovery" only in the Scopus database, it may notice an exponential increase in international scientific production in this field of knowledge (Figure 1). In fact, during a period in which many scientists were unable to be in person in the laboratories and perform bench experiments, many contributions on the development of new drugs against various diseases, including COVID-19, were made by theoretician study involving computational approach of small molecules, proteins and enzymes (Holanda et al., 2021).

Figure 1. Number of documents containing the term "in silico drug discovery" in the Scopus database (19952020).

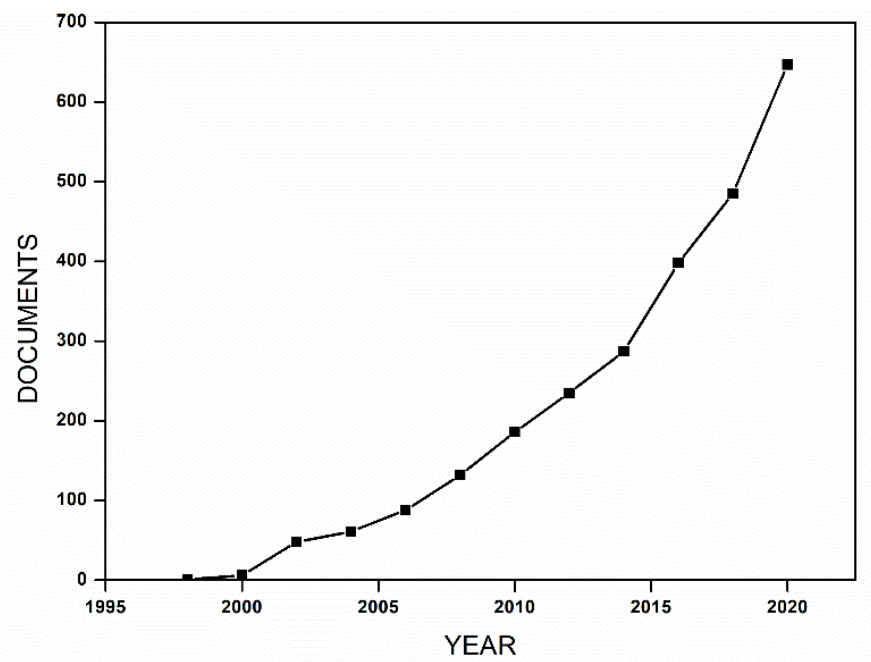

The research and development of drug is a process that is constantly updating - especially by involves different areas of knowledge - which have been consolidating as a multidisciplinary and multifaceted field (Romasanta et al., 2020). As with raltegravir, an HIV integrase inhibitor developed after obtaining important results by molecular dynamics (Casalini, 2021), new drugs will be produced from rational planning and using computational tools, contributing to the understanding mechanism of action, reduced toxicological risk and increased efficacy (Sheik Amamuddy et al., 2020). 


\section{REFERENCES}

BALASUBRAMANIAN, K. Computational and Artificial Intelligence Techniques for Drug Discovery and Administration. In: (Ed.). Reference Module in Biomedical Sciences: Elsevier, 2021. ISBN 978-0-12801238-3.

BRIL, A.; NOSJEAN, O. Editorial overview: New technologies: multidisciplinary evolutions for drug discovery. Current Opinion in Pharmacology, v. 42, p. vii-ix, 2018/10/01/ 2018. ISSN 1471-4892. Available at: $<$

https://www.sciencedirect.com/science/article/pii/S1471 $489218300961>$.

CASALINI, T. Not only in silico drug discovery: Molecular modeling towards in silico drug delivery formulations. Journal of Controlled Release, v. 332, p. 390-417, 2021/04/10/ 2021. ISSN 0168-3659. Available at:

https://www.sciencedirect.com/science/article/pii/S0168 $365921001164>$.

DARWISH, S. M.; SHENDI, T. A.; YOUNES, A. Chemometrics approach for the prediction of chemical compounds' toxicity degree based on quantum inspired optimization with applications in drug discovery. Chemometrics and Intelligent Laboratory Systems, v. 193, p. 103826, 2019/10/15/ 2019. ISSN 0169-7439. Available at:

https://www.sciencedirect.com/science/article/pii/S0169 $743918305495>$.

HOLANDA, V. N. et al. Identification of 1,2,3-triazolephthalimide derivatives as potential drugs against COVID-19: a virtual screening, docking and molecular dynamic study. Journal of Biomolecular Structure and Dynamics, p. 1-19, 2021. ISSN 0739-1102. Available at: < https://doi.org/10.1080/07391102.2020.1871073 >.

MAHDIAN, S. et al. Repurposing FDA-approved drugs to fight COVID-19 using in silico methods: Targeting SARS-CoV-2 RdRp enzyme and host cell receptors (ACE2, CD147) through virtual screening and molecular dynamic simulations. Informatics in Medicine Unlocked, v. 23, p. 100541, 2021/01/01/ 2021. ISSN 2352-9148. Available at:
https://www.sciencedirect.com/science/article/pii/S2352 $914821000319>$.

NIU, G.; LI, W. Next-Generation Drug Discovery to Combat Antimicrobial Resistance. Trends in Biochemical Sciences, v. 44, n. 11, p. 961-972, 2019/11/01/ 2019. ISSN 0968-0004. Available at: < https://www.sciencedirect.com/science/article/pii/S0968 000419301197 >.

PILLAIYAR, T. et al. A medicinal chemistry perspective of drug repositioning: Recent advances and challenges in drug discovery. European Journal of Medicinal Chemistry, v. 195, p. 112275, 2020/06/01/ 2020. ISSN 0223-5234. Available at: < https://www.sciencedirect.com/science/article/pii/S0223 $523420302440>$.

ROMASANTA, A. K. S. et al. Career development in fragment-based drug discovery. Drug Discovery Today: Technologies, 2020/12/01/ 2020. ISSN 1740-6749. Available at: https://www.sciencedirect.com/science/article/pii/S1740 $674920300184>$.

SHEIK AMAMUDDY, O. et al. Integrated Computational Approaches and Tools for Allosteric Drug Discovery. International Journal of Molecular Sciences, v. 21, n. 3, 2020. ISSN 1422-0067.

TEMML, V.; KUTIL, Z. Structure-based molecular modeling in SAR analysis and lead optimization. Computational and Structural Biotechnology Journal, v. 19, p. 1431-1444, 2021/01/01/ 2021. ISSN 2001-0370. Available at: < https://www.sciencedirect.com/science/article/pii/S2001 037021000696 >.

YASUO, N.; ISHIDA, T.; SEKIJIMA, M. Computer aided drug discovery review for infectious diseases with case study of anti-Chagas project. Parasitology International, p. 102366, 2021/04/27/ 2021. ISSN 13835769. Available at: < https://www.sciencedirect.com/science/article/pii/S1383 $576921000842>$. 